\title{
Impact of Helicobacter pylori on hematological parameters among Saudi population
}

Wesam A. Nasif, PhD, Abeer Shaker E. Ali, MSc, Hiba S. Alamodi, PhD, Abeer A. Alrefai, PhD, Atheer A. Alzubedi, MBBCH, Haneen S. Almasoudi, MBBCH, Razan M. Sulaimani, MBBCH, Alaa A. Sulaiman, MBBCH, Aisha A. Alharbi, MBBCH.

\begin{abstract}

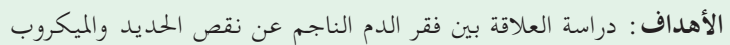

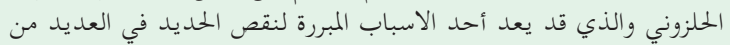

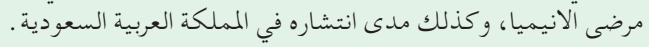

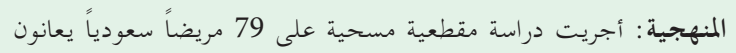

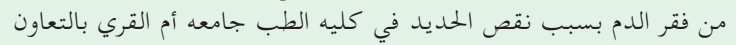

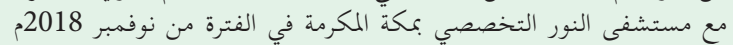

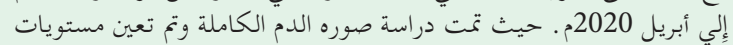

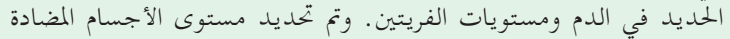

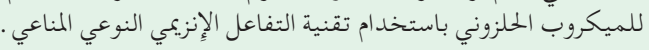

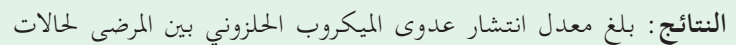

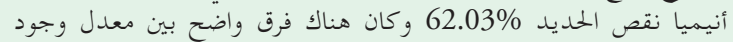

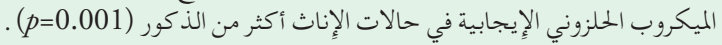

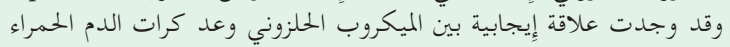

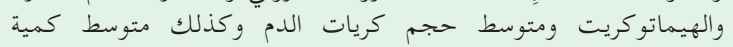

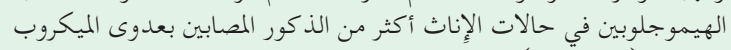
الحلزوني ( العيموجلوين في (

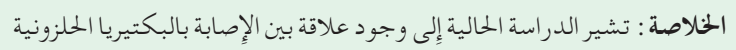

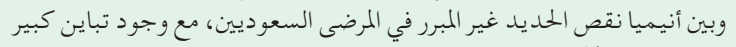

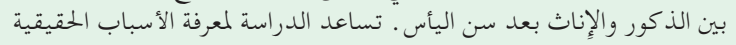

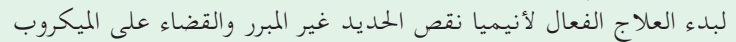

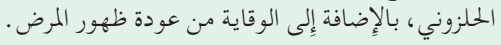

Objectives: To investigate prevalence and association between iron deficiency anemia (IDA) and Helicobacter pylori (H. pylori).

Methods: This cross-sectional study included 79 participants with unexplained IDA. The study was carried out between November 2018 to April 2020 in the College of Medicine, Umm Al-Qura University in collaboration with Al-Noor Specialist Hospital, Makkah, Saudi Arabia. Complete blood count (CBC), serum iron, and ferritin levels were measured. Anti-H. pylori antibody was detected using anti- $H$. pylori immunoglobulin G enzyme-linked immunosorbent assay (ELISA).
Results: The prevalence of $H$. pylori infection among IDA patients was $62 \%$. There was a significant difference between female and male subjects with a positive $H$. pylori status $(p=0.001)$. There was also a significant difference between females and males with a positive $H$. pylori infection according to red blood cell count, hematocrit, mean corpuscular volume, and mean cor-puscular hemoglobin $(p=0.001)$.

Conclusion: The current study shows an association between $H$. pylori infection and unexplained IDA with significant difference between postmenopausal Saudi females and males. This will lead to more effective treatment in IDA and the eradication of $H$. pylori, as well as the prevention of recurrence, which are necessary and may provide a significant reduction in the overall disease burden.

Keywords: H. pylori, IDA, CBC, serum iron, ferritin

Saudi Med J 2021; Vol. 42 (6): 643-648 doi: 10.15537/smj.2021.42.6.20210103

From the Biochemistry Department (Nasif, Alamodi, Alrefai); from the Pathology Department (Ali); and from College of Medicine (Alzubedi, Almasoudi, Sulaimani, Sulaiman, Alharbi), Umm Al-Qura University, Makkah, Kingdom of Saudi Arabia.

Received 15th February 2021. Accepted 18th April 2021.

Address correspondence and reprint request to: Dr. Wesam A. Nasif, Professor of Biochemistry, Faculty of Medicine, Umm Al-Qura University, Makkah, Kingdom of Saudi Arabia. E-mail:wnasif2003@yahoo.com

ORCID ID: https://orcid.org/0000-0002-5119-0137

Disclosure. Authors have no conflict of interests, and the work was not supported or funded by any drug company. 
T he World Health Organization (WHO) recently identified anemia as a world public health issue, as 1.62 billion members of the world's population are anemic. ${ }^{1}$ Iron deficiency is commonly assumed to cause most anemia worldwide and is responsible for $75 \%$ of all third-world anemia cases, affecting $30 \%$ of the population. ${ }^{2}$ The average prevalence of iron deficiency anemia in Saudi Arabia is 30\%-56\%. ${ }^{3}$ Established causes of iron deficiency include when iron consumption is low, iron absorption is poor, or frequent iron losses occur beyond small bowel absorption. If the iron balance cannot be preserved, iron reserves will slowly decline, and iron deficiency anemia (IDA) will develop. ${ }^{4}$ In addition to the above mentioned causes, iron deficiency anemia may occur as a result of chronic gastrointestinal (GI) blood loss, which is the greatest common effect in males and postmenopausal females. ${ }^{3,5}$

Half of the world's population is believed to have Helicobacter pylori (H. pylori), with higher prevalence in developing countries. ${ }^{6}$ It is a spiral shaped gram-negative pathogenic bacterium, which inhabits the gastric epithelium directly, causing a variety of acute and chronic gastrointestinal disorder, including peptic ulcer disease, chronic gastritis, or gastric disease. ${ }^{7}$ Away from the stomach, over 50 extra-gastric manifestations of H. pylori involving IDA have been recorded. ${ }^{8}$

Helicobacter pylori is possibly responsible for iron deficiency anemia through several mechanisms, including occult chronic GI bleeding due to gastric mucosal micro-erosions. Hypochlorhydria can allow ascorbic acid to be converted to dehydroascorbic acid, a less active form that prevents iron absorption by reducing the ferric to the ferrous form, which is important for non-haem iron absorption. ${ }^{9,10}$

Helicobacter pylori competes with the host for iron absorption by possessing certain outer membrane proteins that facilitate tissue lesions, in particular cytotoxin-associated gene A (CagA), vacuolization cytotoxin A (VacA), and heat shock proteins (HSPS), ${ }^{11,12}$ which play a role in the absorption of bacterial iron and intracellular storage of ferritin-like proteins. ${ }^{13}$ Efficient eradication of $H$. pylori in patients with unexplained IDA leads to the improvement of hemoglobin, iron, total blood-binding ability, and ferritin levels. ${ }^{5}$

The goal of this study was, through a cross-sectional study, to measure the prevalence of $H$. pylori infection among patients with IDA of unknown etiology in Saudi patients; as well as, to assess $H$. pylori infection association with hematological parameters among these patients.
Methods. A cross-sectional study was conducted on 79 Saudi patients (31 males and 48 females) who were diagnosed with IDA of an unknown cause, and the mean age was $42.62 \pm 10.82$ years old (range 21-68 years). Patients who were registered through the current study had dyspepsia and epigastric and vague abdominal pain. Patients with chronic or hemorrhagic disorders, celiac disease, overweight or obese or inappropriate weight loss, IG bleeding, chronic diarrhea, intractable vomiting, acid suppression medication, or new proton pump inhibitor (PPI) therapy were excluded. Thirty age- and gender- matched healthy volunteers as a control were enrolled in the current study which was conducted in the College of Medicine, Umm Al-qura University in collaboration with Al-noor Specialist Hospital, Makkah, Saudi Arabia, between November 2018 and April 2020. The ethical approval was obtained from the Research Ethics Committee of Faculty of Medicine, Umm Al Qura University, Makkah, Saudi Arabia, and all patients and volunteers provided informed consent form. Adequate blood samples were collected. Blood was drawn and placed in standard ethylenediamine tetraacetic acid vacutainers for analysis the complete blood count $(\mathrm{CBC})$ assay and plain tubes for anti- $H$. pylori immunoglobulin G (IgG) antibody assays, iron and ferritin. The separated serum was split into aliquots. One aliquot was used for ferritin and iron estimation, and the remaining aliquots were kept at $70^{\circ} \mathrm{C}$ for anti- $H$. pylori $\operatorname{IgG}$ antibody estimation.

Diagnosis of iron deficiency anemia. A hemoglobin levels of $<13 \mathrm{~g} / \mathrm{dL}$ in male subjects and $<12 \mathrm{~g} / \mathrm{dL}$ in female subjects were identified as IDA according to WHO criteria. ${ }^{14}$ The mean corpuscular volume (MCV) was $<80 \mathrm{fL}$, the serum iron was $<37 \mathrm{~g} / \mathrm{dL}$, and the serum ferritin was $<13 \mathrm{ng} / \mathrm{mL}$. Electro-chemiluminescence (Elec Sys 2010 analyzer; Roche Diagnostics, Mannheim, Germany) was used to evaluate serum ferritin levels, while a CobasIntegra700 analyzer was used to determine serum iron levels (Roche Diagnostics, Basel, Switzerland). The CBC assays were carried out on a SysmexSE-9000 automated analyzer (Kobe, Japan), which was calibrated regularly with the manufacturer's standards.

Determination of anti-H. pylori IgG. For evaluation of $H$. pylori satus, the titer of anti-H.pylori antibodies was measured, using anti-H. pylori IgG enzyme-linked immunosorbent assays (ELISA) to detect and evaluate qualitatively serum IgG antibodies to $H$. pylori infected subjects. A value less than 0.9 was deemed negative for the presence of detectable IgG antibodies against $H$. pylori, while a value greater than 1.1 indicated positive IgG antibodies against $H$. pylori. 
Statistical analysis. The Statistical Package for Social Sciences, version 20 (IBM Inc., Chicago, IL, USA was applied for all statistical analyses. Continuous (numerical) data are represented by the mean standard deviation, while categorical (discrete) data are represented by numbers (percentages). The student's $\mathrm{t}$-test and the Mann-Whitney $\mathrm{U}$ test were used to assess if there were statistically meaningful variations between classes. The Pearson correlation test was used to measure correlation coefficients. $P$-values $<0.05$ were regarded as important.

Results. Prevalence of $H$. pylori. Seventy-nine percent with unknown causes of IDA who participated in our study, 31 males (39.2\%) and 48 females (60.8\%) with ages ranging from 21 to 68 years (mean age: 42.62 \pm 10.82 years) were included. The healthy controls involved $18(60 \%)$ men and 12 (40\%) women, with a mean age of $37.6 \pm 11.84$ years. In IDA patients and non-anemic healthy controls, the prevalence of $H$. pylori infection was 49 out of $79(62.03 \%)$ and 7 out of 30 $(23.33 \%)$, respectively. This distinction was statistically important $(p=0.001)$ (Figure 1).

Hematological parameters among IDA and control group. Table 1 displays the hematological results. Hemoglobin values were smaller than the reference range of $12 \mathrm{~g} / \mathrm{dL}$, with a mean value of 9.7 \pm 1.17 compared to $13.94 \pm 0.80$ in the control group ( $p=0.0001)$. Values of the red blood cells (RBCs) count, mean corpuscular volume (MCV), hematocrit (HCT), and mean corpuscular hemoglobin $(\mathrm{MCH})$

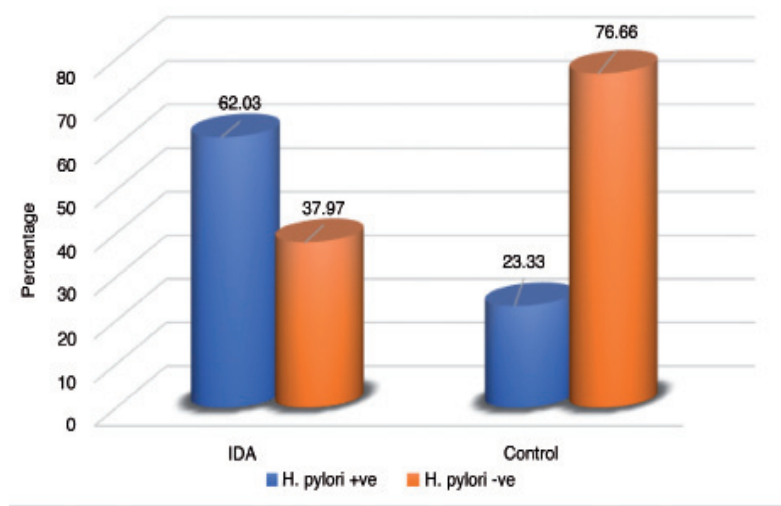

Figure 1 - Prevalence of $\mathrm{H}$. pylori in the unexplained iron deficiency anemia and control groups. IDA, unexplained iron deficiency anemia group $(\mathrm{n}=79)$; HC, healthy control group $(\mathrm{n}=30)$. Mean values were significantly different between groups $(p<0.001)$. H. pylori: Helicobacter pylori, +ve: positive, -ve: negative
Table 1 - Hematological data of the patients with unexplained iron deficiency anemia.

\begin{tabular}{|c|c|c|c|}
\hline $\begin{array}{l}\text { Parameter of } \\
\text { hematology } \\
\text { indexes }\end{array}$ & $\begin{array}{l}\text { IDA } \\
\text { study group } \\
(\mathrm{n}=79)\end{array}$ & $\begin{array}{c}\text { Control group } \\
\quad(n=30)\end{array}$ & $P$-value \\
\hline Age (years) & $44.86 \pm 10.08$ & $41.98 \pm 8.39$ & 0.16 \\
\hline $\begin{array}{l}\text { RBC } \\
\left(4.2-5.1 \times 10^{6} / \mu \mathrm{L}\right)\end{array}$ & $3.81 \pm 0.29$ & $4.85 \pm 0.37$ & 0.0001 \\
\hline $\begin{array}{l}\text { Hemoglobin } \\
(12-15 \mathrm{~g} / \mathrm{dL})\end{array}$ & $9.7 \pm 1.17$ & $13.94 \pm 0.80$ & 0.0001 \\
\hline HCT (36-52\%) & $33.96 \pm 3.41$ & $41.48 \pm 2.93$ & 0.0001 \\
\hline MCV (80-98 ft) & $72.6 \pm 5.2$ & $86.24 \pm 4.19$ & 0.0001 \\
\hline $\mathrm{MCH}(28-34 \mathrm{pg})$ & $23.68 \pm 2.73$ & $29.64 \pm 1.20$ & 0.0001 \\
\hline $\begin{array}{l}\mathrm{MCHC} \\
(32-36 \mathrm{~g} / \mathrm{dL})\end{array}$ & $30.57 \pm 1.96$ & $33.64 \pm 0.97$ & 0.0001 \\
\hline $\begin{array}{l}\text { Serum iron } \\
(40-165 \mu \mathrm{g} / \mathrm{dL})\end{array}$ & $27.8 \pm 10.89$ & $78.2 \pm 23.61$ & 0.0001 \\
\hline $\begin{array}{l}\text { Ferritin } \\
(13-280 \mathrm{ng} / \mathrm{dL})\end{array}$ & $7.6 \pm 4.12$ & $89.7 \pm 56.21$ & 0.0001 \\
\hline \multicolumn{4}{|c|}{$\begin{array}{l}\text { Values are presented as mean } \pm \text { SD. SD: standard deviation, IDA: iron } \\
\text { deficiency anemia, RBC: red blood cell count, HCT: hematocrit, } \\
\text { MCV: mean corpuscular volume, MCH: mean cor-puscular } \\
\text { hemoglobin, MCHC: mean corpuscular hemoglobin concentration }\end{array}$} \\
\hline
\end{tabular}

of the patients in the study group were all lower than those of the control group, which was not surprising. Furthermore, serum iron and serum ferritin levels in IDA patients were found to be relatively higher than in non-anemic healthy controls $(p=0.0001)$.

Detection H. pylori of $\operatorname{IgG}$ antibodies. Since $\mathrm{IgG}$ antibodies are by far the most specific type of anti-bodies for detecting $H$. pylori infection, we examined IgG antibodies in 79 IDA patients and 30 controls for confirmation of $H$. pylori infection. Anti- $H$. pylori IgG antibody status was used to classify the IDA patients into 2 groups; $H$. pylori-positive as group I and $H$. pylori-negative as group II. There was a strong association $(p=0.002)$ between positive $(n=49,62 \%)$ and negative $(\mathrm{n}=30,38 \%) H$. pylori status (Table 2).

Hematological characteristics in IDA with positive and negative $H$. pylori. In both the male and female sample groups, there was a significant difference between the IDA group and those with and without H. pylori infection $(p=0.01)$. However, there were no statistically meaningful discrepancies in $\mathrm{RBC}$, hemoglobin $(\mathrm{Hb}), \mathrm{HCT}, \mathrm{MCV}, \mathrm{MCH}$, serum iron, or ferritin levels between IDA patients with and without $H$. pylori infections (Table 2). In comparison, there was a statistically significant discrepancy in hematological parameters (RBC, Hb, HCT, and $\mathrm{MCV}$ ) between patients and control subjects with a positive $H$. pylori status $(p<0.0001)$. Furthermore, the serum iron concentration and serum ferritin levels in 
Table 2 - Hematological characteristics in patients with and without IDA with positive and negative Helicobacter pylori (H. pylori)infection, compared to the controls.

\begin{tabular}{|c|c|c|c|c|c|c|}
\hline \multirow[b]{2}{*}{$\begin{array}{l}\text { Parameter of the hematology } \\
\text { indexes }\end{array}$} & \multicolumn{3}{|c|}{ IDA Study group ( $n=79$ ) } & \multicolumn{3}{|c|}{ Control group (n=30) } \\
\hline & $\begin{array}{l}\text { Positive } H . \text { pylori } \\
\text { with IDA } \\
(\mathrm{n}=49)\end{array}$ & $\begin{array}{c}\text { Negative } H . \text { pylori } \\
\text { without IDA } \\
(\mathrm{n}=30)\end{array}$ & $P$-value & $\begin{array}{l}\text { Positive } \\
\text { H. pylori } \\
(\mathrm{n}=7)\end{array}$ & $\begin{array}{c}\text { Negative } \\
\text { H. plylori } \\
(\mathbf{n}=23)\end{array}$ & $P$-value \\
\hline Gender, male/female & $18 / 31$ & $13 / 17$ & 0.01 & $4 / 3$ & $14 / 9$ & 0.4 \\
\hline Age (years) & $45.16 \pm 8.56$ & $43.26 \pm 11.23$ & 0.39 & $41.63 \pm 10.76$ & $39.93 \pm 11.26$ & 0.29 \\
\hline $\operatorname{RBC}\left(4.2-5.1 \times 10^{6} / \mu \mathrm{L}\right)$ & $3.74 \pm 0.34$ & $3.86 \pm 0.37$ & 0.14 & $4.62 \pm 0.35$ & $4.87 \pm 0.42$ & $<0.0001$ \\
\hline $\begin{array}{l}\text { Hemoglobin } \\
(12-15 \mathrm{~g} / \mathrm{dL})\end{array}$ & $9.4 \pm 1.62$ & $9.8 \pm 1.51$ & 0.28 & $13.32 \pm 0.76$ & $14.28 \pm 0.89$ & $<0.0001$ \\
\hline HCT (36-52\%) & $33.1 \pm 3.3$ & $33.5 \pm 3.6$ & 0.61 & $40.49 \pm 2.36$ & $41.2 \pm 2.82$ & $<0.0001$ \\
\hline $\operatorname{MCV}(80-98 \mathrm{ft})$ & $72.81 \pm 5.98$ & $73.34 \pm 4.79$ & 0.68 & $86.15 \pm 2.19$ & $87.31 \pm 3.14$ & $<0.0001$ \\
\hline $\mathrm{MCH}(28-34 \mathrm{pg})$ & $22.79 \pm 2.81$ & $23.34 \pm 1.20$ & 0.31 & $28.71 \pm 0.9$ & $29.72 \pm 1.71$ & $<0.0001$ \\
\hline Serum iron $(40-165 \mu \mathrm{g} / \mathrm{dL})$ & $26.2 \pm 8.2$ & $27.4 \pm 11.6$ & 0.56 & $74.67 \pm 22.62$ & $77.89 \pm 21.98$ & $<0.0001$ \\
\hline Ferritin (13-280 ng/dL) & $7.1 \pm 2.7$ & $7.6 \pm 3.6$ & 0.48 & $66.2 \pm 49.81$ & $90.2 \pm 52.96$ & $<0.0001$ \\
\hline
\end{tabular}

There were no statistically significant differences between patients with or without $H$. pylori infections among IDA patients. However, there was a markedly significant difference between $H$. pylori-positive patients and the control group in terms of the hematological parameters $(p<0.0001)$.

Values are presented as mean \pm SD. SD: standard deviation, IDA: iron deficiency anemia, RBC: red blood cell count, HCT: hematocrit, MCV: mean corpuscular volume, $\mathrm{MCH}$ : mean corpuscular hemoglobin, MCHC: mean corpuscular hemoglobin concentration

Table 3 - Corelation between unexpland IDA and positive H. pylori status in males and females.

\begin{tabular}{|c|c|c|c|}
\hline \multirow[b]{2}{*}{$\begin{array}{l}\text { Parameter of the } \\
\text { hematology indexes }\end{array}$} & \multicolumn{3}{|c|}{ IDA with positive $H$. pylori status $(\mathrm{n}=49)$} \\
\hline & $\begin{array}{c}\text { Male } \\
(\mathrm{n}=18)\end{array}$ & $\begin{array}{l}\text { Female } \\
(\mathbf{n}=31)\end{array}$ & $P$-value \\
\hline $\begin{array}{l}\text { RBC } \\
\left(4.2-5.1 \times 10^{6} / \mu \mathrm{L}\right)\end{array}$ & $3.66 \pm 0.26$ & $3.36 \pm 0.31$ & 0.001 \\
\hline $\begin{array}{l}\text { Hemoglobin } \\
(12-15 \mathrm{~g} / \mathrm{dL})\end{array}$ & $10.4 \pm 1.62$ & $8.9 \pm 1.34$ & 0.001 \\
\hline HCT (36-52\%) & $34.9 \pm 2.4$ & $32.0 \pm 3.10$ & 0.001 \\
\hline $\operatorname{MCV}(80-98 \mathrm{ft})$ & $75.79 \pm 3.91$ & $72.32 \pm 3.27$ & 0.001 \\
\hline $\mathrm{MCH}(28-34 \mathrm{pg})$ & $23.74 \pm 1.98$ & $21.38 \pm 2.40$ & 0.001 \\
\hline $\begin{array}{l}\text { Serum iron } \\
(40-165 \mu \mathrm{g} / \mathrm{dL})\end{array}$ & $29.63 \pm 6.46$ & $24.18 \pm 4.97$ & 0.001 \\
\hline $\begin{array}{l}\text { Ferritin } \\
(13-280 \mathrm{ng} / \mathrm{dL})\end{array}$ & $7.8 \pm 1.21$ & $6.35 \pm 1.54$ & 0.001 \\
\hline \multicolumn{4}{|c|}{$\begin{array}{c}\text { There was a significant correlation between male and female IDA cases } \\
\text { with positive } H \text {. pylori with regard to all hematological parameters } \\
(p=0.001) \text {. Serum iron concentration and serum ferritin levels were } \\
\text { significantly lower in female } H \text {. pylori-positive IDA patients than in } \\
\text { male } H \text {. pylori-positive IDA patients }(p=0.001) \text {. }\end{array}$} \\
\hline
\end{tabular}

H. pylori-positive IDA patients were slightly higher than in H. pylori- positive non-anemic controls (Table 2). The prevalence of positive $H$. pylori status in female IDA patients was found to be substantially higher than in male IDA patients $(p=0.001)$.

Unexpland IDA and positive H. pylori in males and females. Table 3 displays a significant relationship between male and female IDA patients with positive $H$. pylori status and all hematological parameters $(p=0.001)$. Also, Table 3 shows that serum iron and ferritin levels were slightly lower in female $H$. pyloripositive IDA patients than in male $H$. pylori-positive IDA patients $(p=0.001)$.

Discussion. The present cross-sectional study aimed to evaluate the $H$. pylori infection prevalence in Saudi patients with unexplained IDA, as well as to explore the association between $H$. pylori infection and the hematological parameters of these patients. Inadequate iron consumption, inadequate iron absorption, or when normal iron losses exceed the small bowel's capacity to absorb iron can result in the loss of iron stores. Iron deficiency anemia is considered a major public health problem. At the same time, $H$. pylori is a common infection of the GI tract, affecting most of the population. ${ }^{15,16}$ Although the guidance on IDA has confirmed the etiological role of H. pylori in IDA, the relationship remains controversial. The most frequent reason for nutritional deficiency causing anemia in clinical practice is iron deficiency. ${ }^{17}$ The results of the current study illustrate that $62.3 \%$ of patients with IDA were positive for $H$. pylori infection. Iron deficiency anemia can occur as a result of $H$. pylori infection through active hemorrhage secondary to gastritis, peptic ulcers, or gastric cancer, achlorhydria caused by chronic pangastritis, and iron utilization by bacteria for colonization. ${ }^{18-20}$

Several previous studies have found a high incidence of $H$. pylori in patients with unexplained or refractory IDA, proving these results. Demerdash et $\mathrm{al}^{6}$ reported that in patients with unexplained or refractory IDA $(61.5 \%), H$. pylori infection is more prevalent than 
in healthy controls (14.3\%). Hershko et $\mathrm{al}^{21}$ reported that in $55 \%$ of the patients examined $(n=300)$ with unexplained IDA, $H$. pylori infection was the common coexisting finding. Another retrospective study by $\mathrm{Xu}$ et $\mathrm{al}^{22}$ noted that the prevalence of anemia among the study group was 5.5\% (428/7804) in infected subjects with $H$. pylori, in comparison to $5.2 \%(522 / 9987)$ in subjects without $H$. pylori infection.

The current study found a significant difference in hemoglobin concentrations between patients with positive $H$. pylori status with IDA and the control subjects $(p<0.0001)$. Additionally, there was a significant difference between female and male subjects with positive $H$. pylori status $(p=0.001)$. With regard to this finding in the current study, our female patient population consisted of postmenopausal-aged women to exclude other significant causes of female anemia, such as different gynecological and sociodemographic variables (fertile age, pregnancy, and lifestyle). Xu et $\mathrm{a}^{22}$ reported a lower value of hemoglobin in the infected group with $H$. pylori for male patients.

The results of our present study showed a significant difference between females and males with a $H$. pylori infection in terms of RBC, HCT, MCV, and $\mathrm{MCH}$ $(p=0.001)$. In addition, the present study illustrated a significant difference in serum iron concentration and serum ferritin levels in patients with a positive $H$. pylori status and control subjects $(p<0.0001)$. A significant difference between males and females in our study group was observed for serum iron concentration and serum iron levels $(p=0.001)$.

A previous study reported that they did not find any differences with respect to iron parameters, even with $H$. pylori infection. ${ }^{21.23}$ Other previous work has found a relationship between $H$. pylori infection and declining levels of ferritin; for example, Parkinson et $\mathrm{al}^{24}$ has found a substantial correlation between low levels of serum ferritin and $H$. pylori infection. As far as we can tell, this is the first study to investigate the presence of a significant difference between males and postmenopausal females by studying the association between unexplained IDA and $H$. pylori infection.

Study limitations. Although this is an attempt to study $H$. pylori that might be of significance in progression of unexplained IDA, only a limited number of cases were investigated here. The present work was limited to patients from a single hospital at Al-Noor Hospital, Makkah, Saudi Arabia.This makes it impossible to deduce the findings to the whole of Saudi Arabia. Another drawback of our research is that we used a cross-sectional design, which might not be the optimal method for establishing a causal association between $H$. pylori infection and patient factors. The follow-up of such patients after eradication of $H$. pylori in the majority of our patients was lost, as many of these patients were referred to other hospitals, leading to a decrease in the evidence for a cause-and-effect association between $H$. pylori infection and "unexplained" IDA.

In conclusion, the GI tract assessment is a key step in the clinical assessment and treatment of IDA patients. A high percentage of patients are often left without a diagnosis. The current study proposes a relationship between $H$. pylori infection and unexplained IDA among Saudi population, with a considerable discrepancy between postmenopausal females and males. This study suggests that screening of $H$. pylori infection and appropriate treatment in any case of unexplained IDA, especially without clinical GI manifestations, will help to achieve a significant reduction in the overall disease burden.

Acknowledgment. The authors thank Afnan A. Al-Yamani, Malak H. Alfaifi, Shatha A. Haroun, Amjad Mashhour N. Altijani, and Alaa A. Abujbal for their efforts in collecting samples and recording data. We would like to thank MDPI editing company "https://www. mdpi.com/authors/english\#English_Editing_Services" for English language editing.

\section{References}

1. Testerman TL, Morris, J. Beyond the stomach: An updated view of Helicobacter pylori pathogenesis, diagnosis, and treatment. World J Gastroenterol 2014, 20: 12781-12808.

2. Soleimani N, Abbaszadeh, N. Relationship Between Anaemia, Caused from the iron deficiency, and academic achievement among third grade high school female students. Procedia Soc Behav Sci 2011; 29: 1877-1884.

3. Bayraktar UD, Bayraktar S. Treatment of iron deficiency anemia associated with gastrointestinal tract diseases. World J Gastroenterol 2010; 16: 2720-2725.

4. Sapmaz F, Başyiğit S, Kalkan İH, Kısa Ü, Kavak EE, Güliter S. The impact of Helicobacter pylori eradication on serum hepcidin-25 level and iron parameters in patients with iron deficiency anemia. Wiener klinische Wochenschrift 2016; 128: 335-340.

5. Goldberg ND. Iron deficiency anemia in patients with inflammatory bowel disease. Clin Exp Gastroenterol 2013; 6: 61-70.

6. Demerdash DME, Ibrahim H, Hassan DM, Moustafa H, Tawfik NM. Helicobacter pylori associated to unexplained or refractory iron deficiency anemia: An Egyptian single-center experience. Hematol Transfus Cell Ther 2018; 40: 219-225.

7. Sethi A, Chaudhuri M, Kelly L, Hopman W. Prevalence of Helicobacter pylori in a first Nations population in northwestern. Ontario Can Fam Physician 2013; 59: e182-e187.

8. Franceschi F, Zuccalà G, Roccarina D, Gasbarrini A. Clinical effects of Helicobacter pylori outside the stomach. Nat Rev Gastroenterol Hepatol 2014; 11: 234-242. 
9. Annibale B, Capurso G, Martino G, Grossi C, Delle Fave G. Iron deficiency anaemia and Helicobacter pylori infection. Int J Antimicrob Agents 2000; 16: 515-519.

10. DuBois S, Kearney DJ. Iron-deficiency anemia and Helicobacter pylori infection. Am J Gastroenterol 2005; 100: 453-459.

11. John S, Baltodano JD, Mehta N, Mark K, Murthy U. Unexplained iron deficiency anemia: Does Helicobacter pylori have a role to play? Gastroenterol Rep 2018; 6: 215-220.

12. Capurso G, Lahner E, Marcheggiano A, Caruana P, Carnuccio A, Bordi C, et al. Involvement of the corporal mucosa and related changes in gastric acid secretion characterize patients with iron deficiency anaemia associated with Helicobacter pylori infection. Aliment Pharmacol Ther 2001; 15: 1753-1761.

13. Tan S, Noto JM, Romero-Gallo J, Peek RM Jr. Amieva MR. Helicobacter pylori perturbs iron trafficking in the epithelium to grow on the cell surface. PLoS Pathog 2011; 7: e1002050.

14. World Health Organization. Worldwide Prevalence of Anemia 1993-2005: WHO Global Database on Anemia. [Updated 2021. Accessed 2020 June 17]. Available from: https://www. who.int/nutrition/publications/micronutrients/anaemia_iron_ deficiency/9789241596657/en/

15. Pérez-Pérez GI, Israel DA. Role of iron in Helicobacter pylori: Its influence in outer membrane protein expression and in pathogenicity. Eur J Gastroenterol Hepatol 2000; 12: 1263-1265.

16. Malfertheiner P, Megraud F, O'Morain C, Bazzoli F, El-Omar E, Graham D, et al. Current concepts in the management of Helicobacter pylori infection: The Maastricht III consensus report. Gut 2007; 56: 772-781.
17. Lopez A, Cacoub P, Macdougall IC, Peyrin-Biroulet L. Iron deficiency anaemia. Lancet 2016; 387: 907-916.

18. Warren JR, Marshall B. Unidentified curved bacilli on gastric epithelium in active chronic gastritis. Lancet 1983; 321: 1273-1275.

19. Rostami-Nejad M, Aldulaimi D, Livett H, Rostami K. $H$. pylori associated with iron deficiency anemia even in celiac disease patients; strongly evidence based but weakly reflected in practice. Gastroenterol Hepatol Bed Bench 2015; 8: 178-182.

20. Martín de Argíla C, Boíxeda D. Extradigestive manifestations of Helicobacter pylori infection. Science or fiction? Medicina Clinica 2000; 114: 308-317.

21. Hershko C, Hoffbrand AV, Keret D, Souroujon M, Maschler I, Monselise Y, et al. Role of autoimmune gastritis, Helicobacter pylori and celiac disease in refractory or unexplained iron deficiency anemia. Haematologica 2005; 90: 585-595.

22. Xu MY, Cao B, Yuan BS, Yin J, Liu L, Lu QB. Association of anaemia with Helicobacter pylori infection: A retrospective study. Sci Rep 2017; 7: 13434.

23. Gheibi SH, Farrokh-Eslamlou HR, Noroozi M, Pakniyat A. Refractory iron deficiency anemia and Helicobacter Pylori Infection in pediatrics: A review. Iran J Ped Hematol Oncol 2015; 5: 50-64.

24. Parkinson AJ, Gold BD, Bulkow L, Wainwright RB, Swaminathan B, Khanna B, et al. High prevalence of Helicobacter pylori in the Alaska native population and association with low serum ferritin levels in young adults. Clin Diagn Lab Immunol 2000; 7: 885-888. 